\title{
Anatomical derangements after failed PSARP: correlating MRI and operative findings
}

\author{
Amr Abdelhamid AbouZeid ${ }^{1 *}$ (D) and Shaimaa Abdelsattar Mohammad²
}

\begin{abstract}
Background: Redo surgery for anorectal anomalies (ARA) may be considered a special category of reconstructive surgery with less predictable outcomes. In this report, we studied anatomical derangements in a group of boys following a previously complicated PSARP procedure, in addition to the effect of reoperation on rectifying this distorted anatomy.

Results: The study included 27 boys who were re-operated after a previous complicated PSARP. Included cases were divided into two groups: group A (14 cases) was referred before colostomy closure with an obviously complicated primary operation, and group B (13 cases) was referred with delayed complications after colostomy closure.

Pelvic MRI examinations were performed before reoperation in 19 cases. In nine of these cases, a repeat MRI examination was performed at follow-up after reoperation to study the effect of redo surgery on rectifying the distorted anatomy.

Abnormal wide anorectal angle and wide pelvic hiatus were common anatomical derangements after a previously complicated PSARP. An important goal of reoperation was reconstruction of the levator ani behind the anorectum trying to create a more acute anorectal angle and a narrower pelvic hiatus. The success of this corrective step was evaluated by MRI comparing pre- and postoperative measurements that showed a favourable decrease in the values of anorectal angle and hiatal/PC ratio. Improvement of faecal continence was documented after reoperation in 8 out of 10 cases in group B.

Conclusion: A wide pelvic hiatus was a frequently encountered postsurgical complication after failed PSARP that has most probably resulted from poor reconstruction of the pelvic floor at time of the primary repair. Reapproximation of the split halves of levator ani in the midline behind the anorectum at reoperation can help to correct the distorted internal anatomy and improve bowel control in these cases.
\end{abstract}

Keywords: Rectourethral, Rectobulbar, Anorectal malformations, Continence, Imperforate anus

\section{Background}

Redo surgery for anorectal anomalies (ARA) may be considered a special category of reconstructive surgery with less predictable outcomes [1]. Reoperations are directed to manage complications following failed primary repair usually performed at another centre [2]. Surgeons should be well oriented with the original type of ARA, as

\footnotetext{
* Correspondence: amrabdelhamid@hotmail.com

${ }^{1}$ Pediatric Surgery Department, Faculty of Medicine, Ain Shams University, Cairo, Egypt

Full list of author information is available at the end of the article
}

well as the possible complications following different reconstructive procedures $[3,4]$. Different surgical procedures may be associated with different forms of postsurgical complications. For example, anterior anal retraction is the most common complication after anterior sagittal anorecto-plasty (ASARP) [5], while lateral misplacement of anorectum [4] may be more common after abdominal pull-through procedures. Posterior urethral diverticulum used to be seen more frequently following the early attempts of laparoscopic repair of rectourethral fistula [6]. 
Most reports in the literature have discussed causes of failure of primary operations for ARA based on external anatomical derangements and electrical muscle stimulation tests, as well as operative findings at reoperation by experienced surgeons [2, 3]. In this report, we tried to project our previous experience studying the internal pelvic MRI anatomy of ARA [7] to define anatomical derangements in a group of boys following a previously complicated PSARP procedure, in addition to the effect of reoperation on rectifying this distorted anatomy.

\section{Methods}

Data retained by the author for cases of ARA who underwent reoperations during the period 2009 through 2019 was retrospectively analysed. In this report, we only included boys who underwent a previous PSARP and were referred for reoperation either after a failed primary repair or for poor faecal continence. Reoperations after repaired recto-perineal/vestibular fistula were excluded being discussed in a previous report [5]; also, reoperations for more severe types of ARA (cloaca, recto-bladder neck fistula) were beyond our scope in this report. Cases who underwent "minor" day-case reoperations either for anal mucosal ectropion or superficial anal stenosis (Heineke-Mikulicz stricturoplasty) [8] were excluded as well.
Preoperative investigations included conventional contrast studies: enemas, distal colostograms (those referred before closure of colostomy), and urethrograms (in cases with persistent rectourethral fistula). MRI represented an important tool to explore the internal pelvic anatomy searching for possible causes of failed primary repair and possible means of correction. The technique of pelvic MRI has been explained in detail in previous reports [7]. Based on our previous experience, important key planes for studying ARA were identified. The anorectal angle and relative hiatal distance (hiatal/PC ratio) were measured in mid sagittal plane (Fig. 1), which have been shown in a previous study to correlate with continence scores after PSARP [7]. The degree of posterior misplacement of anorectum was best demonstrated in the axial I-plane in relation to ischial tuberosities (Fig. 2). In some older children, a repeat pelvic MRI study (without need for anaesthesia) was performed after reoperation which was available for comparison with the initial MRI study (Figs. 1 and 3). Faecal continence was assessed according to Krickenbeck classification of postoperative outcomes [9].

\section{Operative technique}

A posterior sagittal approach was used in all except two cases. The latter had good location of their neo-anus but
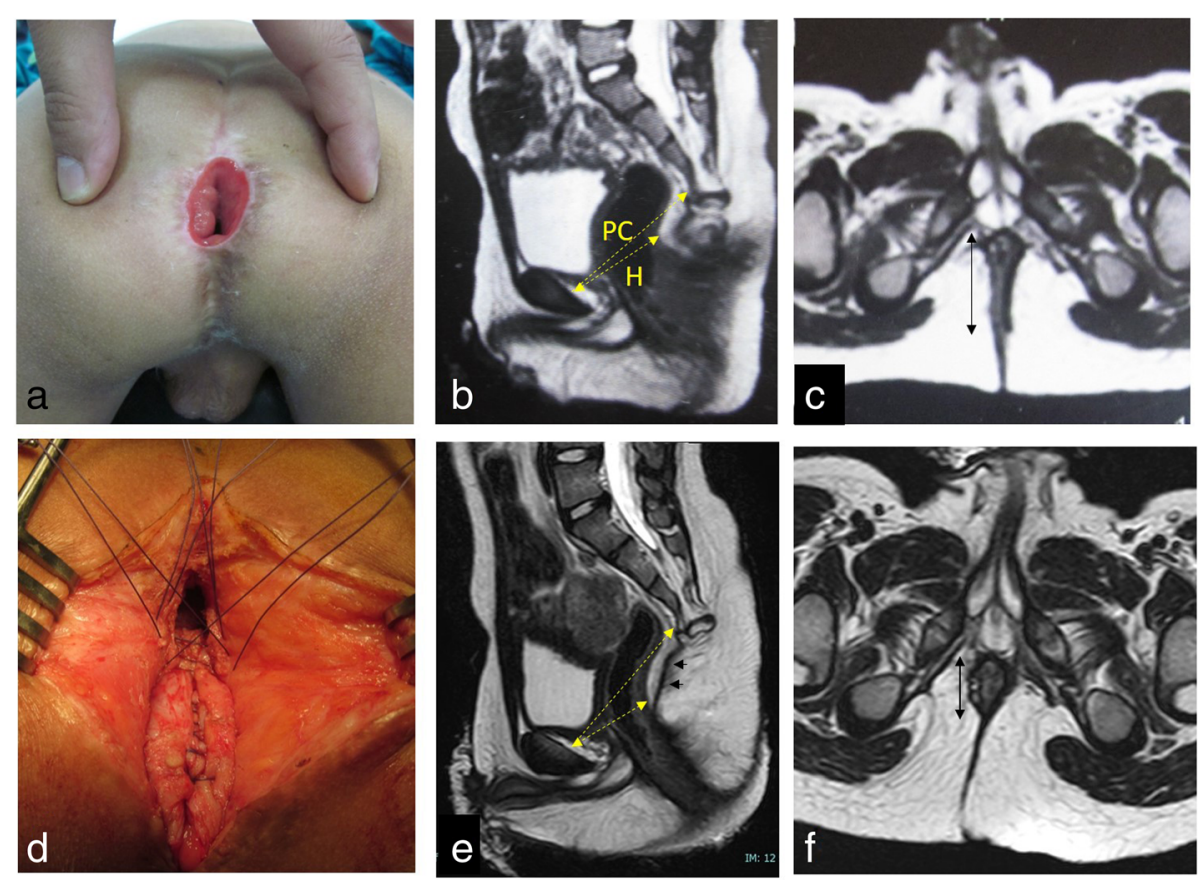

Fig. 1 Five-year-old boy presenting with faecal incontinence after PSARP. a Patient in the prone position, note the patulous anus. b Mid sagittal pelvic MRI (T2WI) demonstrating wide pelvic hiatus $(H)$ with reference to Pubo-Coccygeal distance $(P C)$; [calculated H/PC ratio $=0.7$ ]. c Axial pelvic MRI (I-plane) demonstrating elongated transverse section of the anorectum (double arrow-head line). $\mathbf{d}$ Patient placed in the prone position at reoperation (Redo PSARP): reconstruction of the pelvic floor by re-approximation of the split halves of the diaphragmatic part of the levator ani behind the anorectum. Note: posterior tapering of anorectum. e, f Follow-up MRI (midsagittal and axial, respectively) performed 3 years later after reoperation demonstrating the effect of redo surgery on the internal pelvic MRI anatomy; note: short black arrows are pointing to the reconstructed levator plate behind anorectum; calculated [H/PC ratio $=0.58$ ] (compare with $\mathbf{b}, \mathbf{c}$ ) 

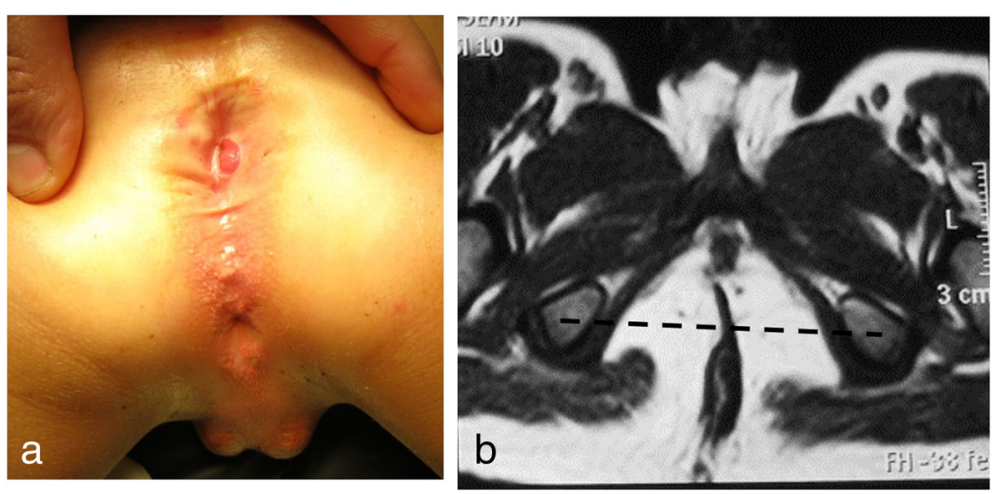

Fig. 2 Eight-year-old boy presenting with complications after a previous PSARP. a Clinical appearance of a posteriorly located anus. b Axial pelvic MRI (I-plane) demonstrating posterior misplacement of anorectum in relation to an imaginary line (dotted line) joining both ischial tuberosities

with persistent rectourethral fistula when an anterior sagittal approach was preferred. The operation was usually performed without covering colostomy except for those who were referred before colostomy closure. At operation, adequate mobilization of the anorectum is important to avoid tension at the ano-cutaneous anastomosis and decrease the risk of postoperative wound complications. If we have any doubt about the viability of the mobilized rectum, a protective colostomy was performed if was not already present (a single case in this
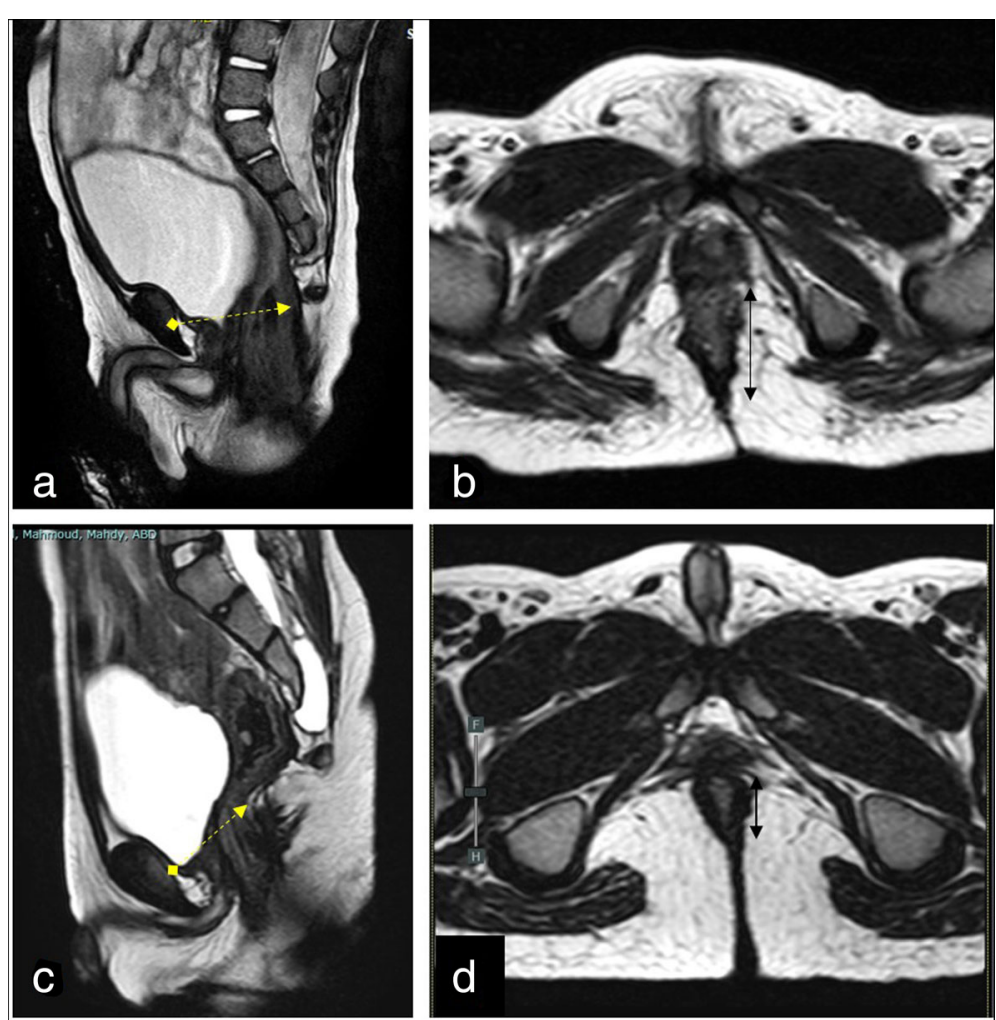

Fig. 3 Demonstration of the effect of reoperation (redo PSARP) on rectifying the distorted internal pelvic anatomy. Upper row (before reoperation): pelvic MRI of 19-month-old boy presenting with complications after a previous PSARP (before closure of colostomy). a Midsagittal MRI demonstrating very wide pelvic hiatus (almost occupying the entire anteroposterior diameter of bony pelvis) with flat anorectal angle. $\mathbf{b}$ Axial MRI (I-plane) demonstrating elongated transverse section of the anorectum (double arrow-head line). Lower row (after reoperation): repeat pelvic MRI at follow-up (5 years later) after redo PSARP (reconstruction of pelvic diaphragm). c Midsagittal MRI demonstrating narrower pelvic hiatus and restored anorectal angulation. $\mathbf{d}$ The effect on the transverse section of the anorectum is demonstrated in axial MRI (I-plane). Note: The progression of a small anterior meningocele through a small sacral defect (compare $\mathbf{c}$ and $\mathbf{a}$ ) 
study). The surgical technique depends on effective mobilization of the anorectum by dissection directly on the rectal wall to avoid injury to surrounding pelvic structures. A rectourethral fistula (if present) will need to be divided and reinforced by a second layer coverage to decrease risk of recurrence. Tapering of the anorectum (posteriorly) may be needed in cases of dilated rectum (Fig. 1d). An important step in a redo PSARP was reconstruction of the pelvic floor through effective closure of the diaphragmatic part of the levator ani behind the rectum (Fig. 1d); a step which was frequently found to be defective after the primary failed operation.

\section{Results}

The study included 27 boys with ARA who were reoperated after a previous complicated PSARP procedure. Except in one case, all primary operations were performed at other hospitals. Their age at reoperation ranged from 1 to 13 years (mean 3.5, median 2). Included cases were divided into two groups: group A (14 cases) represented those who were referred before colostomy closure with an obviously complicated primary operation, and group B (13 cases) were referred with delayed complications after colostomy closure. The indications for reoperation in both groups are summarized in Table 1.

Sacral anomalies were detected in four cases (14.8\%). Severe sacral dysplasia (three missing vertebrae) was present in one case, absent last sacral vertebra was detected in another two cases, and a last case had an anterior sacral defect through which a small meningocele was herniating (Fig. 3).

The most common indications for reoperation were anal retraction and posterior misplacement of the anorectum (Fig. 2). In the latter, the neo-anus was seen mislocated behind the limits of the anal sphincter whose site was confirmed by muscle stimulator at time of operation

Table 1 Indications for reoperation in both study groups

\begin{tabular}{lll}
\hline Complications after primary repair & $\begin{array}{l}\text { Group A } \\
\text { (14 cases) }\end{array}$ & $\begin{array}{l}\text { Group B } \\
\text { (13 cases) }\end{array}$ \\
\hline Anal retraction & 2 & 1 \\
Anal retraction + posterior misplacement & 3 & 2 \\
$\begin{array}{l}\text { Anal retraction + persistent rectourethral } \\
\text { fistula }\end{array}$ & 2 & \\
Rectal prolapse & 4 & 2 \\
Rectal prolapse + posterior misplacement & 1 & 1 \\
Posterior misplacement of neo-anus & 2 & 1 \\
$\begin{array}{l}\text { Persistent rectourethral fistula (urine } \\
\text { passing through anus during micturition) }\end{array}$ & & 2 \\
Faecal incontinence & & 4 \\
\hline
\end{tabular}

Group $A$, those who were referred before colostomy closure with an obviously complicated primary operation; Group B, those who were referred with delayed complications after colostomy closure
(Fig. 2a). Pelvic MRI examination well-demonstrated the posterior misplacement of anorectum in relation to an imaginary line joining both ischial tuberosities (axial Iplane; Fig. 2b). Rectal prolapse was another common indication (eight cases). The wide calibre of the prolapsed neo-anus may indicate for the unjustified discarding of a significant portion of the distal rectum at the primary operation. Faecal incontinence alone was not considered an indication for reoperation unless associated with significant internal anatomical derangement in MRI (Table 1).

To study anatomical derangements after the previous "complicated" PSARP, pelvic MRI examinations were performed before reoperation in 19 cases (70\%). In nine of these cases, a repeat MRI examination was performed at follow-up after reoperation to study the effect of redo surgery on rectifying the distorted anatomy (Figs. 1 and 3 ). These cases were old enough at follow-up to perform the repeat MRI study without anaesthesia. Abnormal wide anorectal angle and wide pelvic hiatus were common anatomical derangements among cases referred for reoperation after a previously complicated PSARP. Values of anorectal angle and hiatal/PC ratio of the 19 cases were generally higher than previously determined cut-off values (Fig. 4); the latter was calculated in a previous study to differentiate between good and poor continence scores after PSARP [7]. Based on MRI findings, an important goal of reoperation was reconstruction of the pelvic diaphragm (levator ani) behind the anorectum trying to create a more acute anorectal angle and a narrower pelvic hiatus (Figs. 1 and 3). The success of this corrective step was evaluated by MRI comparing preand postoperative measurements that showed a favourable decrease in the values of anorectal angle and hiatal/PC ratio. This was tested statistically by the Wilcoxon signed rank test showing $p$-values of 0.07 and 0.01 , respectively (Fig. 5).

Regarding the functional outcome after reoperations, 16 cases were available at follow-up over a period that ranged from 1 to 10 years (mean 4.1, median 3). Table 2 summarizes the functional outcome after reoperation in group A, while Table 3 demonstrates the continence before and after reoperation in group B. Overall, voluntary bowel motions were present in 11 out of 16 cases. However, faecal soiling was almost a constant finding (15/16) after reoperation, in contrast to constipation that was present in only four cases. Improvement of faecal continence was documented after reoperation in 8 out of 10 cases in group B (Table 3).

\section{Discussion}

The goal of different operations for ARA is to achieve faecal continence [2]. Continence depends on the interaction of several innate factors mainly the type of ARA, developmental status of sacrum, and associated spinal 


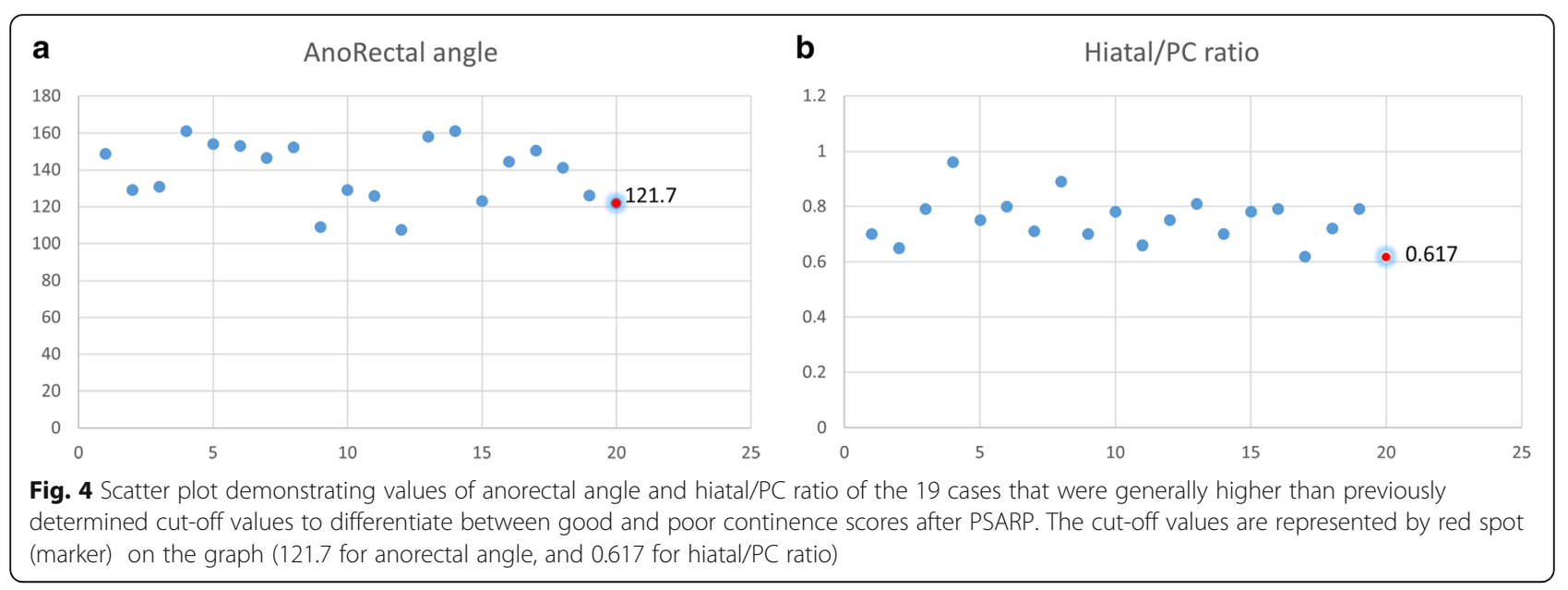

anomalies, in addition to technical factors related to the reconstructive procedure [10]. The type of ARA usually dictates the approach for reconstructive surgery. While PSARP is the standard approach for rectourethral fistula in most centres all over the world [11], a modified/limited technique (ASARP) may be preferred for rectoperineal/vestibular fistula [12]. A higher anomaly (rectobladder neck) will require abdominal or laparoscopic approach.

Based on his huge experience with the repair of ARA (both primary and redo cases), Pena emphasized on some important technical considerations $[2,3]$. Dissection of perirectal fascia is an essential step for effective rectal mobilization. This is important to avoid a common postoperative complication which is anal retraction due to excessive tension at the anocutaneous anastomosis [2]. Dissection should be directly on the rectal wall to avoid damage to surrounding pelvic structures and innervation; also, one should avoid breaching the rectal wall during dissection that would affect the viability of the mobilized rectum through interruption of its submucosal vascular plexus [3]. Lastly, preservation of the rectum is necessary to keep the sensory component for continence in these cases born with deficient anal canal [13].
Reviewing the literature, reports on redo PSARP highlighted several indications and findings at reoperation [2-4]. These included anal strictures, mislocations, prolapse, and missed/persistent fistulae with the urinary tract. In this report, we may add another technical cause based on preoperative anatomical MRI studies. The PSARP represents a peculiar operative technique, which comprise midline incision through the diaphragmatic portion of the levator ani to reach and mobilize the rectum via a perineal approach. Reapproximation of the levator ani in the midline behind the mobilized anorectum is an important step at the end of the procedure. Missing this essential step would end with an abnormally wide pelvic hiatus and straight trajectory of the anorectum through the defective pelvic diaphragm, which can be objectively assessed by MRI through measuring the relative hiatal distance and anorectal angle in mid sagittal images. This characteristic distorted internal pelvic anatomy was detected in a great proportion of cases presenting after a failed PSARP. This observation may prove to be important in different ways:

1. It represents a postsurgical complication specific to PSARP that comprise midline incision of the
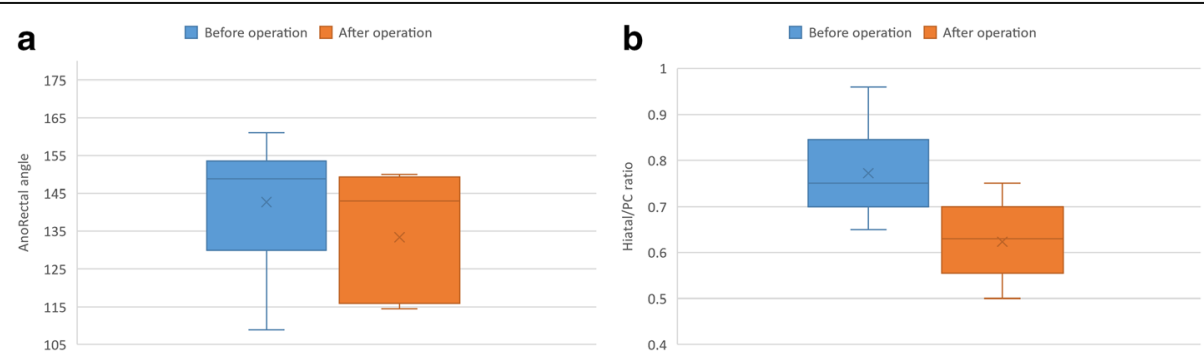

Fig. 5 Statistical analysis comparing pelvic MRI measurements (anorectal angle and hiatal/PC ratio) before and after reoperation. A favorable decrease in the values of anorectal angle and hiatal/PC ratio was detected (Wilcoxon signed rank test; $p$-values $=0.07$ and 0.01 , respectively) 
Table 2 The functional outcome after reoperation and closure of colostomy in group A

\begin{tabular}{|c|c|c|c|c|c|c|c|}
\hline \multirow[t]{2}{*}{ No. } & \multirow[t]{2}{*}{$\begin{array}{l}\text { Age at } \\
\text { reoperation }\end{array}$} & \multirow[t]{2}{*}{$\begin{array}{l}\text { Associated } \\
\text { anomalies }\end{array}$} & \multirow[t]{2}{*}{$\begin{array}{l}\text { Indication for } \\
\text { reoperation }\end{array}$} & \multicolumn{3}{|c|}{$\begin{array}{l}\text { Functional assessment (Krickenbeck classification } \\
\text { of postoperative outcomes) after reoperation and } \\
\text { closure of colostomy }\end{array}$} & \multirow[t]{2}{*}{$\begin{array}{l}\text { Follow-up } \\
\text { duration }\end{array}$} \\
\hline & & & & $\begin{array}{l}\text { Voluntary bowel } \\
\text { control }\end{array}$ & $\begin{array}{l}\text { Grade of faecal } \\
\text { soiling }\end{array}$ & $\begin{array}{l}\text { Grade of } \\
\text { constipation }\end{array}$ & \\
\hline 1 & 2 years & - & Rectal prolapse & No & 3 (severe) & 0 & 10 years \\
\hline 2 & 1 year & $\begin{array}{l}\text { Small anterior } \\
\text { meningocele }\end{array}$ & Rectal prolapse & No & 2 (moderate) & 2 (moderate) & 5 years \\
\hline 3 & 1 year & - & Rectal prolapse & Yes & 2 (moderate) & 0 & 8 years \\
\hline 4 & 1 year & - & Rectal prolapse & Yes & 2 (moderate) & 0 & 10 years \\
\hline 5 & 1.5 years & Trisomy 13 & $\begin{array}{l}\text { Anal retraction + posterior } \\
\text { misplacement }\end{array}$ & Yes & 2 (moderate) & 0 & 5 years \\
\hline 6 & 2 years & $\begin{array}{l}\text { Poor sacrum } \\
\text { (missing } 3 \text { vertebrae) }\end{array}$ & $\begin{array}{l}\text { Anal retraction + posterior } \\
\text { misplacement }\end{array}$ & No & 3 (severe) & 0 & 4 years \\
\hline
\end{tabular}

diaphragmatic part of levator ani as a fundamental step in the procedure.

2. It can be objectively identified preoperatively either directly by measuring the pelvic hiatus (relative hiatal distance) or indirectly by measuring the anorectal angle.

3. It is a correctable complication at reoperation. The two split halves of the levator ani muscle are dissected and re-approximated in the midline behind the anorectum. By pushing the anorectum forward towards the urinary tract, a narrower pelvic hiatus and a more acute anorectal angle are created. Again, the effect of reoperation can be assessed by postoperative MRI.

The role of the levator ani (pelvic floor) in controlling the process of defecation is well known and has been discussed by several researchers. Douglas Stephens highlighted the importance of the puborectalis (the anterior portion of the levator ani) in maintaining continence and recommended pulling the rectum close to the urinary tract anterior to the levator ani [14]. Ninan and Puri reported on the successful use of levatorplasty in children with secondary faecal incontinence [15]. They described a technique of detaching the posterior attachments of the levator ani from the bony pelvis while plicating the diaphragmatic part of the muscle behind the anorectum to create a more acute anorectal angle [15]. Here, we did not perform levatorplasty, but we just aimed to re-approximate the split halves of levator ani behind the anorectum, a step that has most probably been missed at the primary failed operation.

The functional outcome after reoperations of ARA might be expected to be less favourable than following technically sound primary operations [13]. This fact has

Table 3 The functional assessment (continence) before and after reoperation in group B

\begin{tabular}{|c|c|c|c|c|c|c|c|c|c|}
\hline & \multirow{2}{*}{$\begin{array}{l}\text { Age at } \\
\text { reoperation } \\
\text { (in years) }\end{array}$} & \multicolumn{3}{|c|}{$\begin{array}{l}\text { Functional assessment before } \\
\text { reoperation }\end{array}$} & \multirow[t]{2}{*}{$\begin{array}{l}\text { Indication for } \\
\text { reoperation }\end{array}$} & \multicolumn{3}{|c|}{$\begin{array}{l}\text { Functional assessment after } \\
\text { reoperation }\end{array}$} & \multirow[t]{2}{*}{$\begin{array}{l}\text { Duration of } \\
\text { Follow-up }\end{array}$} \\
\hline & & $\begin{array}{l}\text { Voluntary } \\
\text { bowel } \\
\text { control }\end{array}$ & $\begin{array}{l}\text { Grade of } \\
\text { faecal } \\
\text { soiling }\end{array}$ & $\begin{array}{l}\text { Grade of } \\
\text { constipation }\end{array}$ & & $\begin{array}{l}\text { Voluntary } \\
\text { bowel } \\
\text { control }\end{array}$ & $\begin{array}{l}\text { Grade of } \\
\text { faecal } \\
\text { soiling }\end{array}$ & $\begin{array}{l}\text { Grade of } \\
\text { constipation }\end{array}$ & \\
\hline 1 & 5 & No & 3 (severe) & 3 (severe) & $\begin{array}{l}\text { Anal retraction + posterior } \\
\text { misplacement }\end{array}$ & Yes & 1 (mild) & 2 (moderate) & 1 year \\
\hline 2 & 5 & No & 3 (severe) & 3 (severe) & $\begin{array}{l}\text { Anal retraction + posterior } \\
\text { misplacement }\end{array}$ & Yes & 1 (mild) & 2 (moderate) & 2 years \\
\hline 3 & 13 & No & 3 (severe) & 0 & Faecal incontinence & No & 3 (severe) & 0 & 2 years \\
\hline 4 & 1 & & 3 (severe) & 0 & $\begin{array}{l}\text { Rectal prolapse }+ \text { posterior } \\
\text { misplacement }\end{array}$ & Yes & 2 (moderate) & 0 & 3 years \\
\hline 5 & 7 & No & 3 (severe) & 0 & Faecal incontinence & Yes & 2 (moderate) & 0 & 3 years \\
\hline 6 & 5 & No & 3 (severe) & 3 (severe) & Anal retraction & Yes & 2 (moderate) & 2 (moderate) & 6 years \\
\hline 7 & 1 & & 3 (severe) & 0 & Rectal prolapse & No & 3 (severe) & 0 & 2 years \\
\hline 8 & 5 & No & 3 (severe) & 0 & Faecal incontinence & Yes & 2 (moderate) & 0 & 2 years \\
\hline 9 & 3 & No & 3 (severe) & 0 & Rectal prolapse & Yes & 2 (moderate) & 0 & 1 year \\
\hline 10 & 2 & Yes & 2 & 0 & Persistent rectourethral fistula & Yes & 0 & 0 & 2 years \\
\hline
\end{tabular}


led many surgeons to be more reluctant to perform reoperations unless there is a clear expected benefit to be accomplished from the redo surgery [3]. In this case series, we could correct some obvious complications before closure of colostomy in group A (retraction, mislocation, prolapse, persistent fistula). Also, in group B (those referred after closure of colostomy), improvement in bowel control could be identified after reoperation in $80 \%$ of cases. Although voluntary bowel control was present in $68 \%$ of cases, yet full continence (without faecal soiling) was quite rare. Therefore, most of these cases should be advised to keep on dynamic and protracted programmes of bowel management to help them to achieve the desired social continence [10].

\section{Conclusion}

In cases of ARA referred for reoperation after failed PSARP, a wide pelvic hiatus was a frequently encountered postsurgical complication that has most probably resulted from poor reconstruction of the pelvic floor at time of the primary repair. Re-approximation of the split halves of levator ani in the midline behind the anorectum at reoperation can help to correct the distorted internal anatomy and improve bowel control in these cases.

\section{Abbreviations}

ARA: Anorectal anomalies; PSARP: Posterior sagittal anorecto-plasty; ASARP: Anterior sagittal anorecto-plasty; MRI: Magnetic resonance imaging

\section{Acknowledgements}

None

\section{Authors' contributions}

Data acquisition was performed by all authors. AAA made the study design, analysis, and data interpretation, as well as drafting of the manuscript. SAM performed critical revision. All authors have read and approved the final manuscript.

\section{Funding}

None

\section{Availability of data and materials}

The datasets used and/or analysed during the current study are available from the corresponding author on reasonable request.

\section{Declarations}

\section{Ethics approval and consent to participate}

Written parental consent was taken before operation in all cases. Owing to the retrospective nature of the study, an IRB number was not required, and the study was approved through expedited review by the scientific/ethical committee of the Pediatric Surgery Department (Faculty of Medicine, Ain Shams University).

\section{Consent for publication}

Patient identity did not appear in any part of the manuscript; therefore, consent for publication was not required.

\section{Competing interests}

The authors declare that they have no competing interests.

\section{Author details}

${ }^{1}$ Pediatric Surgery Department, Faculty of Medicine, Ain Shams University, Cairo, Egypt. '²epartment of Radiodiagnosis, Faculty of Medicine, Ain Shams University, Cairo, Egypt.

Received: 19 November 2020 Accepted: 19 April 2021

Published online: 08 July 2021

\section{References}

1. Wood RJ, Halleran DR, Ahmed $\mathrm{H}$, et al. Assessing the benefit of reoperations in patients who suffer from fecal incontinence after repair of their anorectal malformation. J Pediatr Surg 2020 (article in press) https://doi.org/https:// doi.org/10.1016/j.jpedsurg.2020.06.011

2. Pena A, Grasshoff S, Levitt M. Reoperations in anorectal malformations. J Pediatr Surg. 2007;42(2):318-25. https://doi.org/10.1016/.jpedsurg.2006.10.034.

3. Pena A, Hong AR, Midulla P, Levitt M. Reoperative surgery for anorectal anomalies. Semin Pediatr Surg. 2003;12(2):118-23. https://doi.org/10.1016/S1 055-8586(02)00022-7.

4. Ahmed H, Halleran DR, Maloof E, et al. Redo posterior sagittal anorectoplasty for lateral mislocation in patients with anorectal malformations. J Pediatr Surg 2020 (article in press) https://doi.org/https:// doi.org/10.1016/j.jpedsurg.2020.05.029

5. AbouZeid AA, Radwan AB, Mohammad SA, et al. Suboptimal correction of low anorectal anomalies: a possible cause for intractable constipation in children. Ann Pediatr Surg. 2016;12(4):142-9. https://doi.org/10.1097/01.XPS. 0000484840.40461 .85

6. Rentea MR, Halleran DR, Vilanova-Sanchez A, et al. Diagnosis and management of a remnant of the original fistula (ROOF) in males following surgery for anorectal malformations. J Pediatr Surg. 2019;54(10):1988-92. https://doi.org/10.1016/j.jpedsurg.2019.02.006.

7. AbouZeid AA, Ibrahim SE, Mohammad SA, et al. Anatomical alterations following the 'PSARP' procedure: correlating MRI findings with continence scores. J Pediatr Surg. 2019;54(3):471-8. https://doi.org/10.1016/j.jpedsurg.2 018.04.025.

8. Halleran DR, Sanchez AV, Rentea RM, Ahmad H, Weaver L, Reck C, et al. Assessment of the Heineke-Mikulicz anoplasty for skin level postoperative anal strictures and congenital anal stenosis. J Pediatr Surg. 2019;54(1):11822. https://doi.org/10.1016/j.jpedsurg.2018.10.006.

9. Holschneider A, Hutson J, Pena A, Bekhit E, Chatterjee S, Coran A, et al. Preliminary reports on the international conference for the developement of standards for the treatment of anorectal malformations. J Pediatr Surg. 2005;40(10):1521-6. https://doi.org/10.1016/j.jpedsurg.2005.08.002.

10. Baxter KJ, Garza JM, Rollins MD, et al. Multi-institutional review of bowel management strategies in children with anorectal malformations. J Pediatr Surg 2020 (article in press) https://doi.org/https://doi.org/10.1016/j. jpedsurg.2020.04.023

11. DeVries PA, Pena A. Posterior sagittal anorectoplasty. J Pediatr Surg. 1982; 17(5):638-43. https://doi.org/10.1016/S0022-3468(82)80126-7.

12. Okada A, Kamata S, Imura K, Fukuzawa M, Kubota A, Yagi M, et al. Anterior sagittal anorectoplasty for rectovestibular and anovestibular fistula. J Pediatr Surg. 1992;27(1):85-8. https://doi.org/10.1016/0022-3468(92)90113-L.

13. Pena A, Bischoff A. Reoperations. In: Surgical treatment of colorectal problems in children. Springer; 2015. p. 349-69.

14. Pena A, Bischoff A. History of the Treatment of Anorectal Malformations. In: Surgical treatment of colorectal problems in children. Springer; 2015. p. 1-16.

15. Ninan GK, Prem P. Levatorplasty using a posterior sagittal approach in secondary faecal incontinence. Pediatr Surg Int. 1994;9:17-20.

\section{Publisher's Note}

Springer Nature remains neutral with regard to jurisdictional claims in published maps and institutional affiliations. 